\title{
Does diet in Celtic Sea fishes reflect prey availability?
}

\author{
V.M. Trenkel ${ }^{1 *}$, J.K. Pinnegar ${ }^{2}$, W.A. Dawson ${ }^{2}$, M.H. du Buit ${ }^{3}$ and A.N. Tidd ${ }^{2}$ \\ ${ }^{1}$ IFREMER, Rue de l'lle d'Yeu, BP 21105, 44311 Nantes cedex 3, France. \\ ${ }^{2}$ CEFAS, Lowestoft Fisheries Laboratory, Lowestoft, NR33 OHT, UK. \\ ${ }^{3}$ CNRS, Collège de France, Laboratoire de Biologie Marine, 29110 Concarneau, France. \\ *: Corresponding author : verena.trenkel@ifremer.fr
}

\begin{abstract}
:
Feeding preferences of Celtic Sea fishes were investigated using a database of stomach content records, collected between 1977 and 1994. The diet of cod Gadus morhua, hake Merluccius merluccius, megrim Lepidorhombus whiffiagonis, whiting Merlangius merlangus and saithe Pollachius virens changed markedly as the animals grew larger, and although large predators generally chose larger bodied prey, the variability of prey sizes consumed also increased. Large predators continued to select small, low value, benthic prey (e.g. Callionymus spp. and Trisopterus spp.) which were easier to catch, rather than larger, more energy lucrative pelagic prey (e.g. mackerel Scomber scombrus), even though these pelagic preyfishes were nearly always available and were often very abundant. Stock estimates of the International Council for the Exploration of the Sea and U.K. groundfish survey catches were used as indices of prey abundance. Bluewhiting Micromesistius poutassou and other small pelagic fishes (Argentina spp. and clupeoids) were identified as being particularly important, and were consumed by some predators more often than would be expected given the abundance of these prey in the environment. There was no evidence for densitydependent feeding by predators on mackerel and only hake exhibited densitydependent feeding on horsemackerel. Hake, cod and megrim consumed more bluewhiting when this prey was at higher abundance in the environment. In choosing what prey to consume, predators must balance costs and benefits, considering the quality of prey and the energy expended during search, capture and handling.
\end{abstract}




\section{INTRODUCTION}

The importance of predation as a regulatory process in marine systems has been well documented and piscivorous fishes are known to have a dramatic influence on population and community level dynamics (see Juanes et al., 2002). However, although a relatively large amount is known about whom eats who in marine systems, virtually nothing is known of the dynamics, and specifically how diets of piscivorous fish relate to changes in the abundance of their prey (Greenstreet et al.,1998).

Most fish are selective foragers; they prefer to feed on some prey types but not on others (Mittelbach 2002). Much of the theoretical development of foraging theory has revolved around trying to explain why predators choose the items they do and whether a predator should theoretically choose to pursue a particular prey item that it has encountered (Mittelbach, 2002). Ecologists have used optimisation criteria to address this question, arguing that natural selection should result in predator behaviours that maximise the rate of energy gain, which is a component of fitness. Charnov (1976) developed one of the first optimal diet models, and three basic predictions stem from this work:

1. predators should prefer prey that yield more energy per unit handling time.

2. as abundance of higher value prey increases in the environment, lower value prey should be dropped from the diet and predators should become more selective.

3. foragers should obey a quantitative threshold rule for when specific prey types should be included or excluded from an optimal diet (Stephens \& Krebs, 1986; Sih \& Christensen, 2001).

Prey encounter rate is dependent on the abundance of that prey in the environment but, in times when a focal prey is not available, predators can satisfy their nutritional and energy requirements, to some extent through adjustments in selection for prey quality. Prey fishes can exhibit a ten-fold difference in lipid content and a five-fold difference in energy density (Anthony et al., 2000). Thus as prey vary in abundance, resource value, catchability and handling time, predators must trade-off costs and benefits to optimise their own survival and reproductive fitness (Stephens \& Krebs, 1986).

As originally formulated, the optimal foraging model of Charnov (1976) considers only diet choice within a homogeneous patch. If the forager moves to another patch the model should ideally be freshly applied and this means that such models cannot be tested by simply looking at stomach contents data and taking overall averages (Stephens \& Krebs, 1986). For example, a predator might forage in a part of the environment where low-quality prey items are disproportionately common, because the abundance of these items might compensate for their low food value. A forager choosing such a patch would appear to take too many low-ranking food and too few high-ranking types compared to an idealized forager for which we would calculate model parameters as if they foraged over the whole environment. In the present study, the validity of optimal foraging theory is not tested, rather it is used as a framework for discussing the trade-offs which consumers face in real systems.

The body mass of many piscivorous fish species can increase by five orders of magnitude during their lives, and a fast-growing animal may begin life as a prey item, only to become the main predator on the same group of species within one year (Jennings et al., 2002). Clearly size is an important determinant of fish diets and many authors (see. Scharf et al., 2000) have attempted to relate physical attributes of the predator (Gape size, length etc.) to the prey found in fish stomachs. 
Over the past 30 years a massive amount of stomach sampling effort has been expended in the North Sea (Pope, 1991), but there has been little concerted research elsewhere in the northeast Atlantic (e.g. the Celtic sea). Marked changes are known to have occurred in the Celtic Sea ecosystem in recent years (Pinnegar et al., 2002), and given such changes it might be expected that the diet of predatory species will have varied in response. (Greenstreet et al., 1998).

The main aims of the present study were to (1) explore how the diet of Celtic Sea fish change with body-size, (2) examine how the size range of the targeted prey change with increasing body-size, (3) explore whether predators select prey in accordance with availability in the environment.

\section{METHODS}

\section{The CeLtic SeA}

The Celtic Sea is an area of continental shelf bordered by Ireland in the North, the UK in the East and the Bay of Biscay ( $47^{\circ} \mathrm{N}$ Latitude line) in the South (Fig. 1). It supports a diverse range of fishing fleets (métiers), characterised by the use of different fishing gear types and different target species (Marchal \& Horwood, 1996). Recent expansion of Celtic Sea fisheries has prompted concern about the present and future state of fish stocks, the scale of fishery discards/by-catch and possible implications for ecosystem functioning as a whole (Pinnegar et al. 2002).

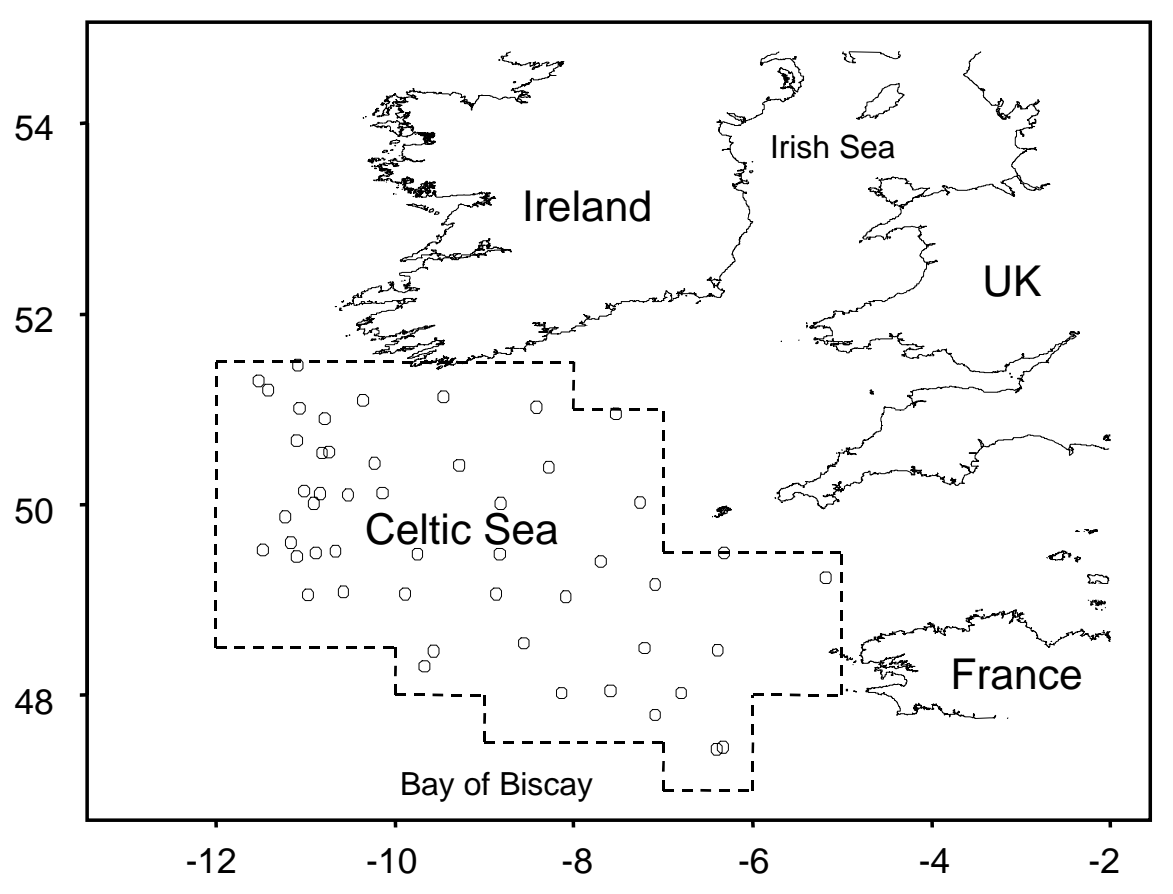

Fig. 1. Area covered by this study, with UK spring-sampling sites indicated by open circles. 
Fish were sampled by UK and French researchers between 1977 and 1994. A total of 26,539 prey items were recorded from 66 predator species (18,129 stomachs).

UK samples were taken as part of annual research cruises aboard the vessels Cirolana, Clione and Scotia. Location, predator length, stomach fullness (on a 10 point scale), prey identity, number and digestion state (on a 4 point scale), were recorded along with the number of empty stomachs. Where possible, prey length was recorded.

French samples were collected aboard commercial trawlers (Agora, Elsinor, Galaxie, Madiana, Melodie, Opera, Peoria, Symphonie, Valériane) during routine fishing operations in the Celtic Sea. These data have been largely documented by Du Buit (1982, 1992, 1995, 1996) but not in the context of prey availability. Predator length, prey identity, prey abundance, prey weight (in grams), and digestion state (on a 5 point scale) were recorded. No data were available relating to non-identifiable prey remains or empty stomachs, also there was no detailed information linking samples to particular geographic locations. Prey length data only existed for megrim Lepidorhombus whiffiagonis (Walbaum), whiting Merlangius merlangus (L.) and saithe Pollachius virens (L.).

Of the 66 fish species for which stomach-content data existed, the number of records was greatest for cod Gadus morhua L., whiting, megrim, hake Merluccius merluccius (L.), haddock Melanogrammus aeglefinus (L.), and saithe. Initial analyses were carried out to determine which of these predators fed mainly on fish (in terms of total numbers of prey items). It was determined that haddock consume very little fish material $(<2 \%$ of all items) and thus this species was excluded from all further analyses.

The temporal coverage of the available data is detailed in Appendix 1. Sampling varied greatly from year to year, with the largest number of stomachs collected in 1984, 1985 and 1991. Stomachs were collected from commercial vessels (1977-1988) throughout the calendar year although sampling was particularly intensive in May, June and October. Stomachs were collected from survey vessels (1990-1994) in March and April each year.

\section{PREY ABUndANCE}

Mackerel Scomber scombrus L., horse-mackerel Trachurus trachurus and blue-whiting Micromesistius poutassou (Risso) were identified as being important fish prey on the basis of their occurrence in the stomachs of cod, whiting, megrim, hake and saithe. Stocks of these pelagic prey species are assessed on an annual basis by ICES (International Council for the Exploration of the Sea), and thus population estimates were available for comparison with fishprey numbers from stomach contents (available vs. consumed prey). Population numbers (in millions) were extracted from the 2002 reports of the 'Northern Pelagic and Blue-whiting Working Group' (WGNPBW) and the 'Working Group on the Assessment of Mackerel, Horsemackerel, Sardine and Anchovy' (WGMHSA). The geographic units considered by ICES, extend beyond the Celtic Sea, thus it was necessary to assume that any temporal patterns apparent at the whole stock level would also be reflected at the Celtic Sea sub-stock level. The abundance of each pelagic species was compared with the stock size of the other two species using a nonparametric Kendall tau test (Conover, 1980).

Abundance estimates for all fish prey species were available from 1982-2003 through the annual ground-fish survey of CEFAS (Centre for Environment, Fisheries \& Aquaculture Science). Samples are collected in March and April each year using a Portuguese High Headline Trawl (PHHT), hauled by the research vessel Cirolana. The distance travelled by the vessel 
whilst hauling, together with the gear geometry (monitored using acoustic transponders) were used to calculate 'swept area' and consequently fish numbers per unit area. Only haul-stations from the central Celtic Sea were included in the analyses (Fig. 1), and the estimated fish density (in numbers per $\mathrm{km}^{2}$ ) was raised to the level of this whole central zone $\left(124,505 \mathrm{~km}^{2}\right)$.

\section{PREY LENGTH}

To estimate changes in median, 'minimum', and 'maximum' prey size with increasing predator body-length, quantile regression techniques were used (Scharf et al. 2000; Scharf et al., 1998). In order to carry out quantile regression, we made use of the BLOSSOM software developed and described by Cade et al. (1999) and Cade \& Richards (1996).

Correlation analyses were performed among 10\% quantile, median (50\% quantile) and $90 \%$ quantile slope estimates to determine whether increases in median prey size were primarily a result of changes in 'minimum' or 'maximum' prey sizes.

\section{PREY-PREFERENCE}

Many prey-selection indices have been proposed, and different indices seem appropriate for answering different ecological questions (Pearre, 1982; Confer \& Moore, 1987). In the present study, we used the index proposed by Chesson $(1978,1983)$ proposed an index $\left(\alpha_{a}\right)$ based on the constant preference coefficient discussed by O’Neill (1969). For a two prey system:

$$
\begin{aligned}
& \alpha_{a}=\frac{r_{a}}{p_{a}} / \sum_{i=1}^{2}\left(\frac{r_{i}}{p_{i}}\right) \\
& =\frac{e}{d} \cdot \frac{a_{d}}{a_{e}} / \frac{e}{d}\left(\frac{a_{d}}{a_{e}}+\frac{b_{d}}{b_{e}}\right)
\end{aligned}
$$

where $a_{d}$ is the number of prey animals of species $a$ in the predator's diet, $b_{d}$ is the number of all other prey animals in the diet, $a_{e}$ is the number of prey animals of species $a$ in the environment and $b_{e}$ is the number of all other prey animals in the environment. $d$ is the total number of all animals in the diet, $e$ is the total number of all animals in the environment and $n$ is the sum $d+e$. $r_{a}$ is the proportion of prey species $a$ in the diet and $P_{a}$ is the proportion in the environment. Here we follow the notion used by Pearre (1982).

$\alpha_{a}$ (also known as the 'standardized forage ratio' $s_{i}$ ) has become popular because of its use in food-web modelling packages (e.g. Christensen et al., 2000). The standardised forage ratio as presented, ranges between 0 and 1 , with $\alpha_{a}=0$ representing complete avoidance and $\alpha_{a}=1$ exclusive feeding. The index is independent of prey availability, and in form is broadly similar to the index $\left(\beta_{\mathrm{Na}}\right)$ proposed by Manly et al. (1972).

Here, $\alpha_{a}$ was calculated on the basis of all available French and English stomach data, irrespective of year. Small sample sizes (Appendix 1) precluded us from calculating meaningful indices on an annual basis. $\alpha_{\mathrm{a}}$ was calculated for a 'portfolio' of seven $(m=7)$ fish-prey species (Argentina spp., Callionymus spp., M. poutassou, S. scombrus, T. trachurus, Trisopterus spp. 
and clupeidae) since these were found to be the most commonly observed fish in the stomachs of cod, hake, whiting, megrim and saithe. Some of these prey 'species' are actually groups of closely related animals (e.g. clupeidae, Trisopterus spp.) which could not be distinguished in stomach contents. In the present case $\alpha_{a}=0.143\left(\alpha_{a}=1 / m\right)$ denotes 'random-feeding', i.e. that the particular prey is taken by the predator in exactly the same proportions as in the environment. Thus $\alpha_{a} 0-0.143$ denotes ‘negative selection' and $0.143-1$ denotes 'positive selection' of a particular prey type.

\section{PREFERENCES VS. CHANGING PREY AVAILABILITY}

Fish-prey abundance, characterised on the basis of UK-survey data or from ICES stock assessments, were compared with the proportion of identifiable fish prey for each year that stomachs were collected. Tests for significance were based on Kendall's tau (Conover, 1980). The rank-based Kendall tau test is a non-parametric method which is particularly robust to outliers. In addition, in order to obtain robust correlation coefficients, $20 \%$ trimming was employed, whereby $20 \%$ of observations were removed - starting with the most extreme (using a routine within the statistical package S-Plus).

\section{RESULTS}

\section{CHANGES IN PREDATOR DIET WITH FISH LENGTH}

The diet of all species were found to change markedly with increasing predator length (Fig. 2). In cod, whiting and hake there was a marked transition from consumption of crustaceans in smaller predators to a higher proportion of fish in the diet of larger animals. Fish never represented more than $40 \%$ of the diet in cod, and polychaetes always represented a small but consistent proportion (Fig. 2d).

Unfortunately, no diet data were available for saithe below the size of $40 \mathrm{~cm}$, possibly because of distributional differences between adult and juvenile animals in the Celtic Sea (Fig. 2e). Diets of large saithe were overwhelmingly dominated by fish prey, but with some cephalopod and pteropod molluscs. Megrim appeared to consume similar proportions of crustaceans and fish throughout their lives, whilst cephalopods also provided a small but consistent contribution (Fig. 2c).

Based on the UK data it was possible to estimate that $64.7 \%$ of all megrim, $11.7 \%$ of hake, $20.4 \%$ of whiting, $19.4 \%$ of saithe and $6.1 \%$ of cod stomachs were empty upon examination. 
a. Hake

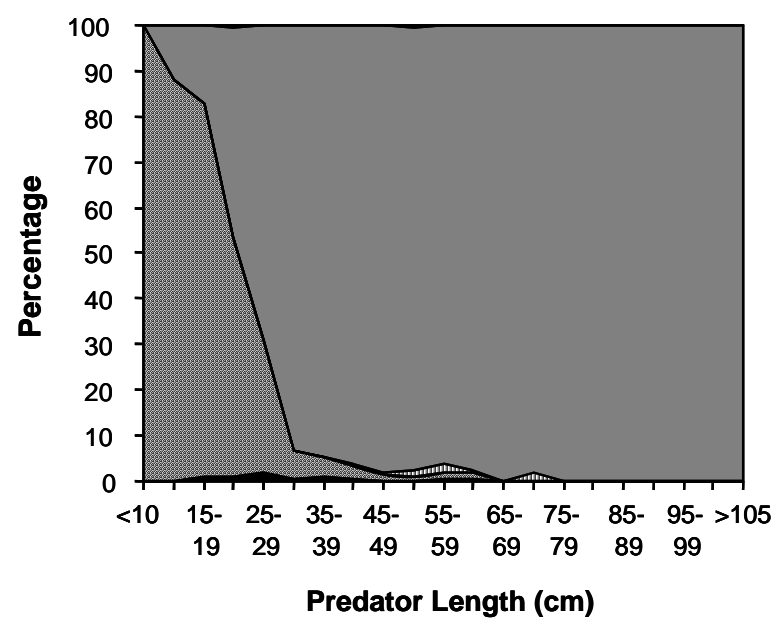

c. Megrim

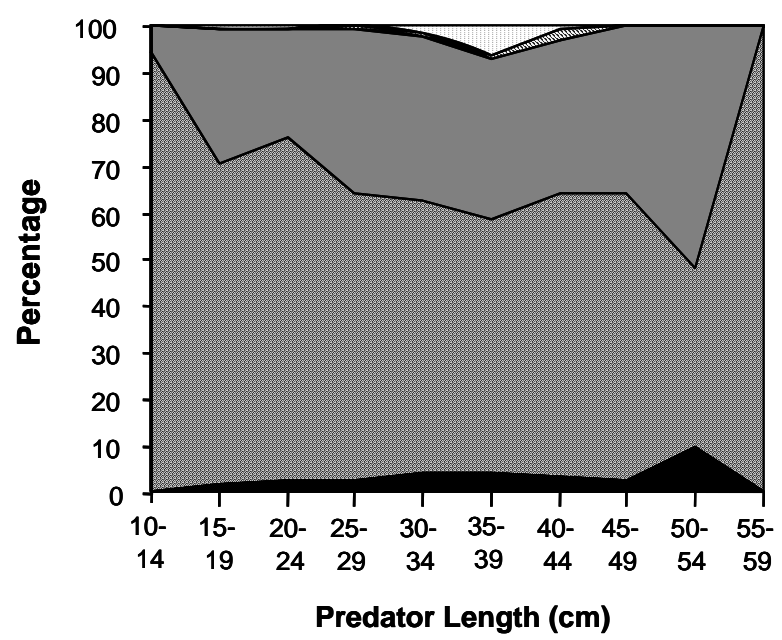

e. Saithe

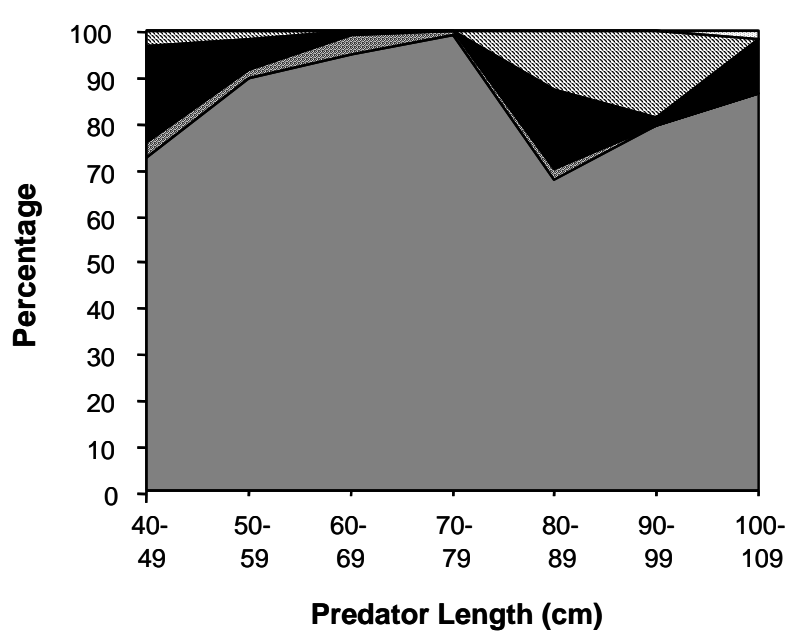

b. Whiting

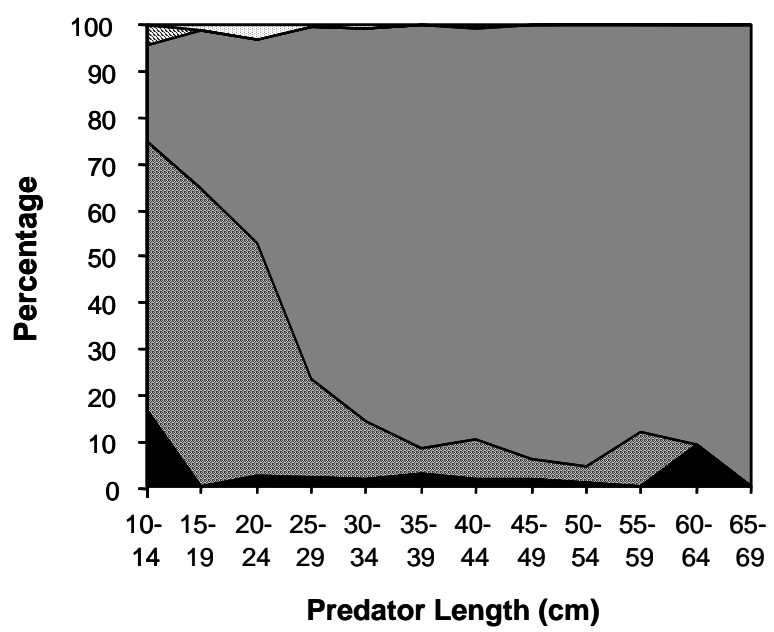

d. Cod

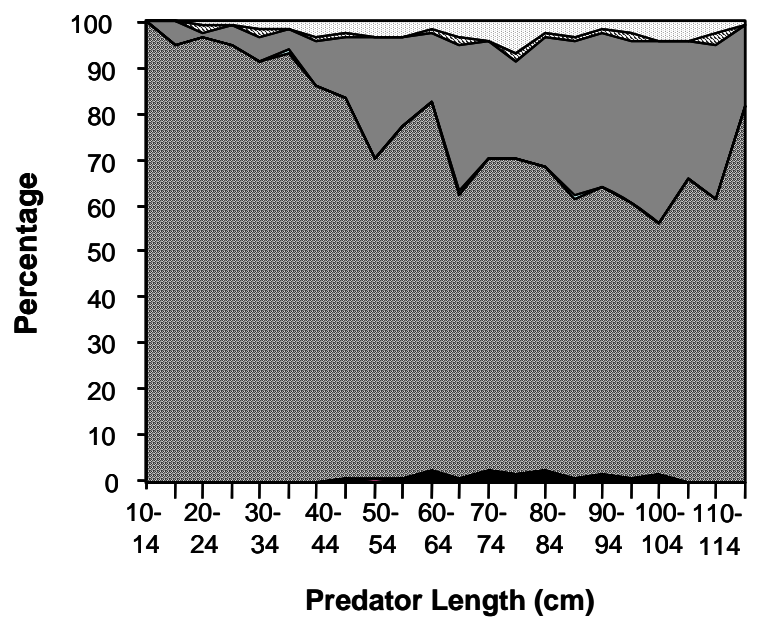

Fig. 2. Changes in the composition of Celtic Sea fish stomach contents with increasing predator body length (in $\mathrm{cm}$ ), based on the number of total prey items 


\section{PREDATOR LENGTH VS PREY LENGTH}

The range of absolute prey sizes eaten expanded with increasing length for all five predators (Fig. 3), thus resulting (particularly in megrim) in highly heteroscedastic error distributions. Upper and lower limits of these relationships ( $90 \%$ and $10 \%$ quantiles) changed at different rates (Table I), and in every case the slope of the relationship between predator length and maximum (90\% quantile) prey size was greater than the slope of the relationship with minimum prey size (10\% quantile) (Table I). This indicated that large predators continued to consume disproportionally small prey, throughout their lives.

Overall, for each predator, prey size increased as predator length increased, and at different size thresholds predators targeted different prey types (Fig. 3). For hake (Fig. 3a) horsemackerel and clupeoids (sardine Sardina pilchardus (Walbaum)) were targeted by larger predators $(>50 \mathrm{~cm})$, whilst blue-whiting, Argentina spp., Trisopterus spp., and small clupeoids (mostly sprat Sprattus sprattus (L.)) were exploited by smaller predators $(<50 \mathrm{~cm})$.

Whiting continued to consume a wide diversity of fish prey throughout their lives (Fig. $3 b)$, although apparently targeting more clupeoids when they were smaller $(<40 \mathrm{~cm})$ and only eating mackerel when they themselves were greater than $40 \mathrm{~cm}$ long and the mackerel were 15 $20 \mathrm{~cm}$ long.

Megrim consumed a wide diversity and size-range of prey (Fig. 3c), including many dragonettes (Callionymus spp.) particularly when predators were smaller than $40 \mathrm{~cm}$, and Trisopterus spp. in larger predators. Blue-whiting and Argentina spp. were consumed over the whole predator length range, but were supplemented with 'other' fish (e.g. gobies, small flatfish etc.) in smaller predators.

The data for cod (Fig. 3d) were relatively sparse (only 110 data points), but it would seem that mackerel (in excess of $20 \mathrm{~cm}$ ) were selected by large predators $(>70 \mathrm{~cm})$, whilst dragonettes and Trisopteus spp. were favoured by predators $<80 \mathrm{~cm}$. Clupeoids $(18-25 \mathrm{~cm})$ were only targeted by cod measuring $45-60 \mathrm{~cm}$.

Data were only available for large saithe $(40-110 \mathrm{~cm})$, which selected mackerel in excess of $15 \mathrm{~cm}$ long and clupeoids/Trisopterus of $6-20 \mathrm{~cm}$. Predators of $80-95 \mathrm{~cm}$ also targeted bluewhiting (Fig. 3e).

The average prey length to predator length ratio was lowest for hake and whiting (Table I). The lower the ratio, the bigger the prey (on average) chosen by the predator. Thus saithe, megrim and cod tended to choose smaller prey relative to their own size, than did hake and whiting. There was no significant correlation between the slopes of the $90 \%$ quantile relationship and the slopes of the median (50\% quantile), across the five predators examined $(r=0.560)$. Similarly there was no significant correlation between the slopes of the $10 \%$ quantile line and that of the median $(r=0.394)$.

Table I. Regression equations (generated using quantile regression techniques) relating median, maximum (90\% quantile) and minimum (10\% quantile) prey length (in $\mathrm{cm})$ to predator length. Only fish prey were considered here.

\begin{tabular}{llllll}
\hline $\begin{array}{l}\text { Predator } \\
\text { Species }\end{array}$ & $\begin{array}{l}\text { Median } \\
(50 \% \text { Quantile })\end{array}$ & $90 \%$ Quantile & $10 \%$ Quantile & $\begin{array}{l}\text { Mean predator-prey } \\
\text { size ratio }( \pm \text { SD })\end{array}$ & $n$ \\
\hline Hake & $\mathrm{y}=0.20 \mathrm{x}+8.51$ & $\mathrm{y}=0.31 \mathrm{x}+10.04$ & $\mathrm{y}=0.19 \mathrm{x}+2.51$ & $2.60 \pm 1.14$ & 267 \\
Megrim & $\mathrm{y}=0.22 \mathrm{x}+1.67$ & $\mathrm{y}=0.33 \mathrm{x}+1.67$ & $\mathrm{y}=0.19 \mathrm{x}-1.31$ & $4.29 \pm 1.95$ & 690 \\
Cod & $\mathrm{y}=0.24 \mathrm{x}+3.44$ & $\mathrm{y}=0.25 \mathrm{x}+8.50$ & $\mathrm{y}=0.13 \mathrm{x}+1.23$ & $4.07 \pm 1.71$ & 110 \\
Whiting & $\mathrm{y}=0.21 \mathrm{x}+4.21$ & $\mathrm{y}=0.29 \mathrm{x}+5.71$ & $\mathrm{y}=0.17+2.67$ & $3.18 \pm 0.99$ & 277 \\
Saithe & $\mathrm{y}=0.14 \mathrm{x}+7.71$ & $\mathrm{y}=0.18 \mathrm{x}+9.21$ & $\mathrm{y}=0.17 \mathrm{x}-0.33$ & $4.57 \pm 1.61$ & 294 \\
\hline
\end{tabular}


a. Hake

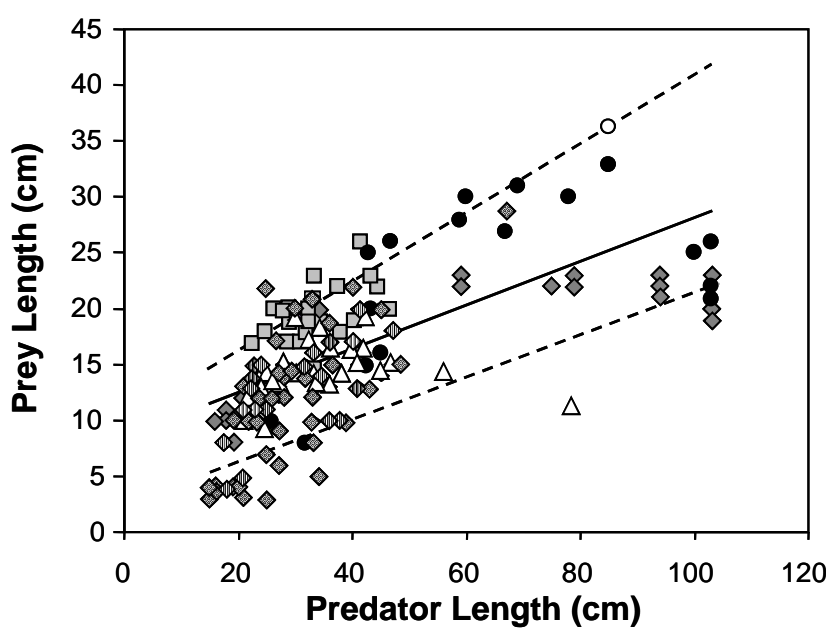

c. Megrim

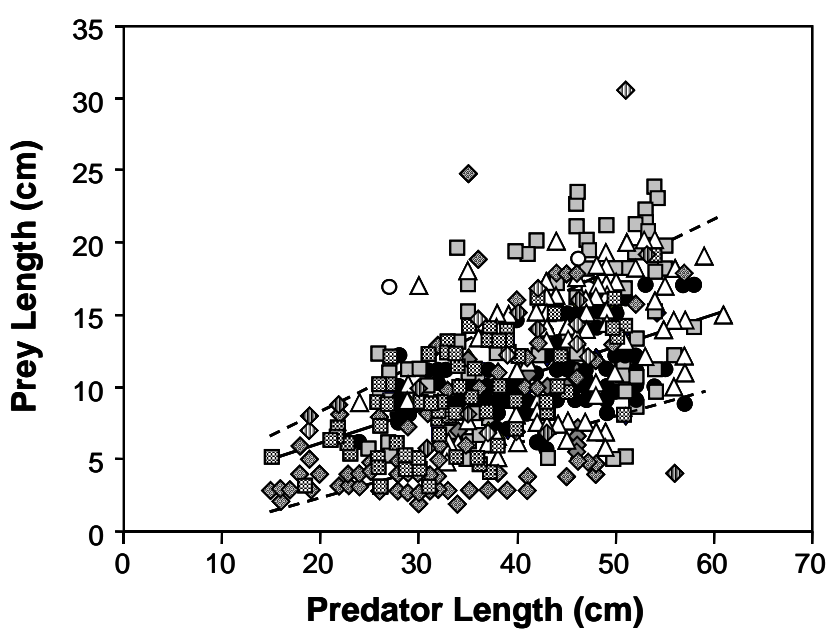

e. Saithe

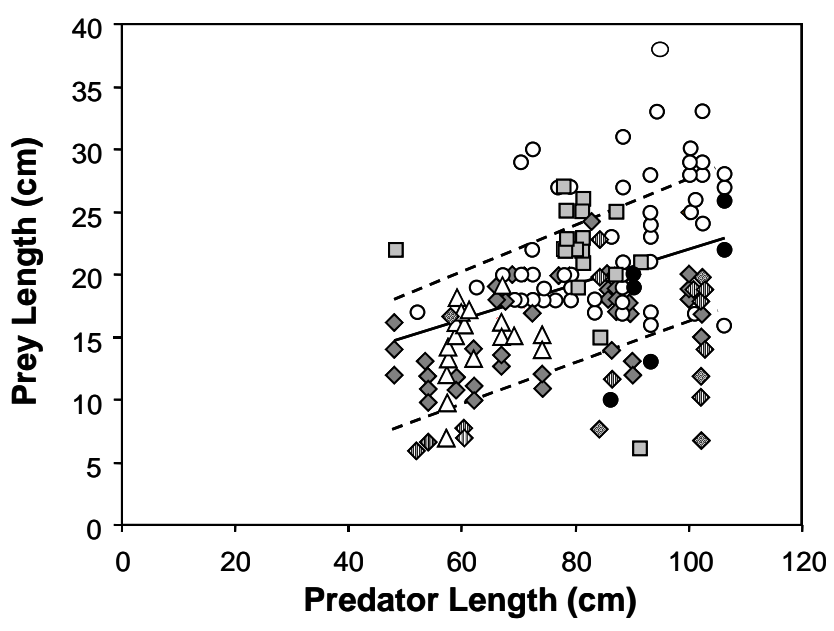

b. Whiting

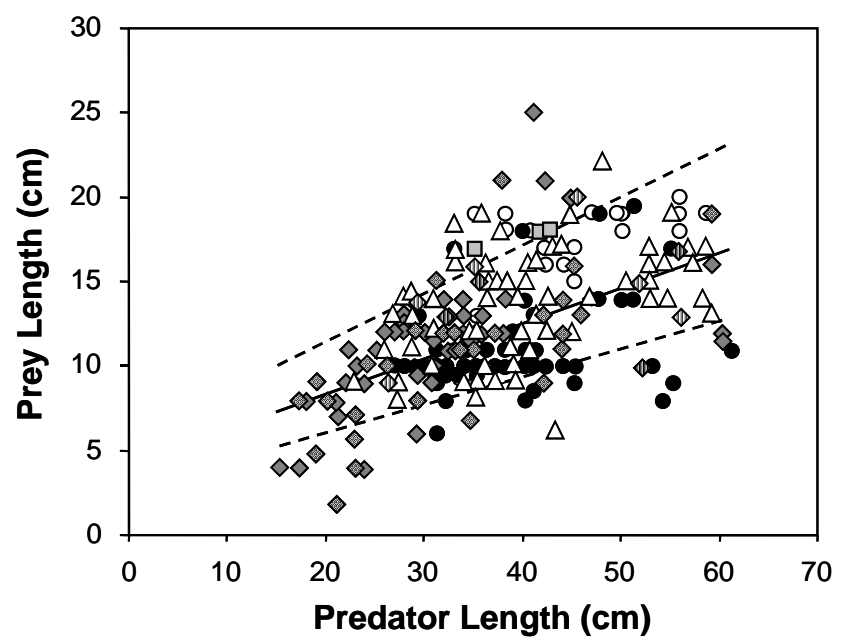

d. Cod

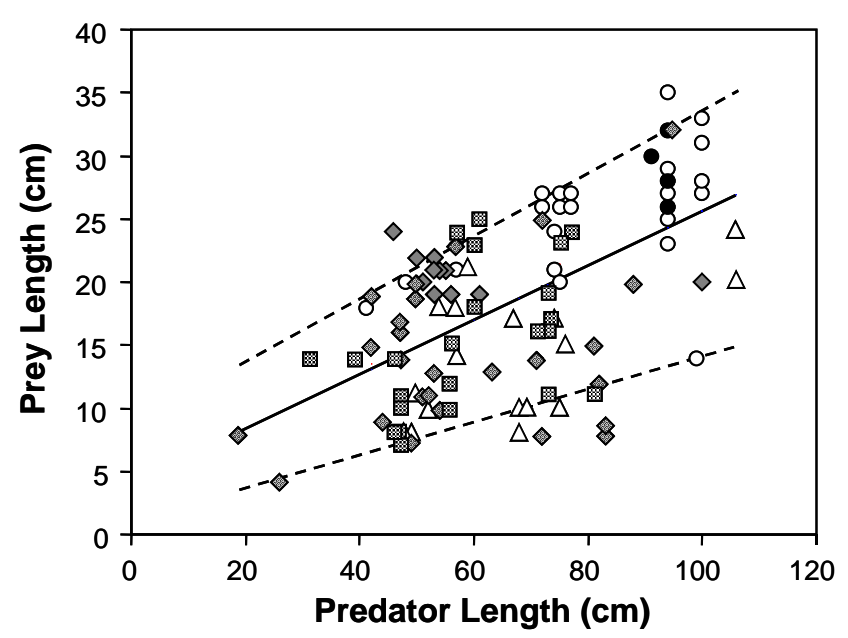

Fig. 3. Length of predator (in $\mathrm{cm}$ ) plotted against the length of prey (fish only) in the stomachs of whiting, hake, cod, megrim and saithe. 
In terms of Chesson's standardized forage ratio $\alpha_{a}$ (Table II), relative to a portfolio of the seven key fish prey; and assuming that anything greater than $0.143\left(\alpha_{a}=1 / k\right)$ represents positive selection, then mackerel, horse-mackerel and Trisopterus spp. were never positively selected. Cod and megrim showed a particular preference for dragonettes (i.e. small benthic fishes), whiting chose clupeoids, saithe chose argentines and clupeoids, whilst hake exhibited a particular preference for all types of small pelagic prey (i.e. blue-whiting, argentines and clupeoids). Pearre (1982) has demonstrated that $\alpha_{\mathrm{a}}$ estimates are not sensitive to the absolute count of potential prey items in the environment, however $\alpha_{a}$ is very sensitive to counts or proportions assumed from the stomach contents data.

Table II. Standardised forage ratio, $\alpha_{\mathrm{a}}$. Preference in relation to a 'portfolio' of seven key-prey types (irrespective of year). The standardised forage ratio as presented, ranges between 0 and 1 , with $\alpha_{a}=0$ representing complete avoidance and $\alpha_{\mathrm{a}}=1$ exclusive feeding. $\alpha_{\mathrm{a}}=0.143$ denotes 'random-feeding'.

\begin{tabular}{|c|c|c|c|c|c|c|c|}
\hline \multirow[b]{2}{*}{$\begin{array}{l}\text { Predator } \\
\text { Name }\end{array}$} & \multicolumn{7}{|l|}{ Prey name } \\
\hline & $\begin{array}{l}\text { Argentina } \\
\text { spp. }\end{array}$ & $\begin{array}{l}\text { Callionymus } \\
\text { spp. }\end{array}$ & Clupeoids & $\begin{array}{l}\text { Blue- } \\
\text { whiting }\end{array}$ & Mackerel & $\begin{array}{l}\text { Horse- } \\
\text { mackerel }\end{array}$ & $\begin{array}{l}\text { Trisopterus } \\
\text { spp. }\end{array}$ \\
\hline Cod & 0.012 & 0.963 & 0.009 & 0.002 & 0.001 & 0.000 & 0.013 \\
\hline Hake & 0.400 & 0.053 & 0.249 & 0.166 & 0.019 & 0.005 & 0.108 \\
\hline Megrim & 0.0760 & 0.855 & 0.039 & 0.007 & 0.000 & 0.000 & 0.023 \\
\hline Saithe & 0.471 & 0.000 & 0.479 & 0.016 & 0.016 & 0.000 & 0.019 \\
\hline Whiting & 0.136 & 0.106 & 0.630 & 0.012 & 0.003 & 0.002 & 0.111 \\
\hline
\end{tabular}

Correlation analyses of ICES stock numbers for mackerel, horse-mackerel and bluewhiting using Kendall's tau test, revealed no significant relationship between horse-mackerel and mackerel stocks $(r=0.341, p=0.056)$. Similarly there was no significant correlation between blue-whiting and mackerel stocks $(r=-0.127, p=0.076)$. Blue-whiting and horse-mackerel numbers were positively related ( $r=0.657, p=0.056$ ), illustrating that horse-mackerel and bluewhiting stocks have exhibited broadly similar temporal dynamics over the past 22 years, whilst temporal patterns were very different in the mackerel stock.

When the proportion of mackerel, horse-mackerel and blue-whiting in predator stomachs was plotted against the availability of these prey as defined by ICES stock assessments, there were many positive trends, demonstrating that predators do select certain preys in proportion to their availability in the environment. However, Kendall's tau indicated that the only significant or near significant correlations were for megrim and hake feeding on blue-whiting ( $p=0.005$ and 0.05 respectively). These data contained many outliers and much variability, largely related to the very limited number of stomachs sampled in some years (Appendix 1). Many of these outliers were effectively removed by the $20 \%$ 'trimming' procedure employed prior to the application of Kendall's tau test.

When the proportion a particular prey represented in stomachs was plotted against the 'availability', as determined by CEFAS spring survey data (spanning 1982-1994), there were again many positive relationships. Because of the marked variability in the data, few of these proved to be statistically significant. Despite the relatively large number of whiting stomachs sampled, there were no instances where the proportion in the stomach and availability in the environment were significantly correlated. Megrim appeared to consume significantly more 
dragonettes and gobies in years when these prey were more abundant ( $p=0.036$ and 0.009 respectively). Cod consumed more blue-whiting when these fish were abundant $(p=0.043)$ and hake chose more horse-mackerel and blue-whiting in years when these prey were more abundant ( $p=0.053$ and 0.053).

In the analyses conducted here, only positive corelations were tested for. There was a clear relationship between consumption of Trispoterus spp. by cod, and the abundance of Trisopterus spp. in the environment. However because this was a strong negative relationship, the test for a positive correlation was rejected $(p=0.958)$.

\section{Discussion}

Examination of stomach contents remains one of the few tools available for understanding the linkages which occur within natural ecosystems. However, we must recognise that stomach content analyses have a number of limitations (Deb, 1997), for example they tend to provide mere snapshots of diets at particular points in time and space, and results depend extensively on the number of samples collected and the subjectivity and taxonomic knowledge of the investigator. Rarely are all links which occur in natural systems adequately quantified using stomach content data (Cohen \& Newman, 1988) and for piscivorous species, an additional problem may stem from the fact that animals regurgitate food upon capture (Bowman, 1986). This might explain the relatively high proportion of apparently empty stomachs observed here for megrim, whiting and saithe.

\section{PREY SIZE}

The analyses presented here demonstrated that for several predator species the proportion of the diet represented by fish greatly increased as the animals became larger. For cod however, the proportion represented by invertebrates remained relatively high, even in large animals and this was unlike the pattern which has been observed in the North Sea, where the fraction of invertebrates in cod diets decrease with increasing body length (Hislop et al., 1997). For cod in the Irish Sea, the decapod Nephrops norveguicus is a very important prey (Armstrong, 1982), and diets-at-length seem on the whole, to be broadly similar to those observed in the Celtic Sea.

Many studies have demonstrated that fish of varying taxonomic groups have an 'optimal' prey size, which is selected if the predator is given a choice (see Hart \& Connellan, 1984). Fish tend to grow faster when feeding on their 'optimal' prey, and models based on particulate feeding fishes suggest that the optimal prey size, should be the largest size that a predator can handle. In the present study it was demonstrated that at various size thresholds (of both the predator and prey), the feeding preference of the predator changes. Thus for example, only above a predator size of $40 \mathrm{~cm}$ and a prey size of $15 \mathrm{~cm}$, do whiting start to consume mackerel. The existence of these apparent size thresholds might be seen as supporting one of the predictions of Optimal Foraging Theory (OFT), that 'foraging should obey a quantitaive threshold rule for when specific prey should be included or excluded from the diet' (Sih \& Christensen, 2001). However, in each case predator size - prey size distributions were highly asymmetric and predators did not always select the largest prey possible, which would presumably provide the best return for each feeding event. Large predators continued to eat small prey, which could be construed as being against one of the other key principles of OFT, that 'predators should prefer prey that yield more energy per unit handling time' (Scharf et al., 2000). In a recent study by Floeter and Temming (2003) it was demonstrated that more than $75 \%$ of fish found in the 
stomachs of North Sea cod originated from the least preferred (i.e. the smallest) quantile of the prey size range. As a consequence, these authors suggested that relative prey abundance rather than prey size preference was by far the dominant force determining composition of fish diet.

Many factors can influence the size and type of prey chosen by a predator (Juanes et al., 2002), these include the effort required to find, pursue and handle the prey, the morphology or visual acuity of the predator the behaviour and habitat use of the prey (which in-turn affect the encounter rate). In the present study, the observation that small prey were retained in the diets of larger predators was not unusual. Scharf et al. (2000) demonstrated similar patterns in 18 species of marine fish (including some of the same species listed here). These authors hypothesised that the combination of high relative abundance and high capture probability for small (often benthic) prey, relative to large (often pelagic) prey, may lead to consistently high vulnerability to predation for small fishes. Schoener (1979) explored the relationships between prey length, profitability and distance at which the prey are first encountered. Schoener noted that the most profitable prey length becomes larger as the encounter distance (and hence the difficulty in pursuing and capturing the prey) increases (Stephens \& Krebs, 1986)

\section{PREY TYPE AND AVAILABILITY}

In balancing costs and benefits, optimally foraging predators can adjust their preferences to take into account prey quality (Anthony et al., 2000). A diet high in lipid provides sufficient metabolizable energy for maintenance, so dietary protein can be allocated to tissue synthesis and growth. Pelagic fishes tend to have a higher lipid content than do demersal or benthic species, hence the observed inclusion of small benthic fishes, (e.g. the dragonettes, Trisopterus spp. And gobies 'positively selected' by cod) may represent a trade-off between the low-value nature of the prey, and the energy saved in pursuit and capture. Interestingly, smaller pelagic species (e.g. blue-whiting and argentines), tend to be more lipid-rich than larger pelagic species (e.g. mackerel) (Van Pelt et al., 1997). As a consequence it might be expected that predators would exhibit a greater preference for these 'small pelagics' when they are available. The $\alpha_{a}$ values estimated here seem to suggest that hake and whiting did prefer small pelagic prey (Aregentina spp., clupeoids and blue-whiting), and there was very little evidence to suggest that either mackerel or horse-mackerel (i.e. larger pelagics) were preferentially selected by any of the five predators considered.

\section{LIMITATIONS OF THE DATA}

Caution must be exercised in interpreting preference indices, in this case $\alpha_{a}$, because the UK survey data, used as an estimate of numbers of prey in the environment (i.e. availability), do not necessarily represent a true picture of the ecosystem. All trawl gears are selective and the choice of sampling method used can greatly affect our perception of the structure and dynamics of the ecological community in a given area (V. Trenkel, unpublished manuscript). The UK spring groundfish survey (using a modified Portuguese High-Headline otter trawl) probably under-estimates the abundance of small benthic fishes, even though it is equipped with bobbins, rubber disks and tickler chains on the groundrope, aimed at specifically increasing the capture efficiency for such species (Engås \& Godø, 1989). A small experimental beam trawl survey carried out in the same area caught many more gobies, dragonettes and flatfishes per unit area, than did the standard UK sampling gear (cod-end mesh 20mm) (V. Trenkel, unpublished manuscript). The overall implications for prey preference indices of not adequately sampling 
small benthic fishes, would be to apparently inflate the suggested preference for these rarer species, at the expense of large-pelagics (mackerel, horse-mackerel, blue-whiting) which dominate in the survey. The UK survey was originally established specifically to investigate the distribution and biology of mackerel (Warnes \& Jones, 1995); it was only widened to cover other more benthic species at a later stage.

In the present paper the proportion of blue-whiting, mackerel and horse-mackerel in the diet of predators were compared with their abundance, as determined by ICES stock assessments. This was completely independent of the UK spring groundfish survey and its associated problems, yet there was again no evidence for density-dependent feeding by predators on either mackerel or horse-mackerel. From these analyses blue-whiting emerged as an important prey for megrim and hake, with consumption relative to other prey animals, increasing in years when blue-whiting stocks were high. The importance of blue-whiting for predators in the Celtic Sea and Bay of Biscay has also been noted by Du Buit (1982) and Velasco \& OlivaTelas (2000).

The number of significant correlations observed between prey abundance and the proportion in the predator stomachs, was relatively low. Thus to answer the question posed in the title of this research paper, we might conclude that the diet of Celtic Sea fishes does not generally reflect prey availability. However, if many such relationships had been found to exist, this would have inferred that piscivorous predators are indiscriminate opportunists, consuming whatever is around and abundant at the time. Such an observation would clearly be inconsistent with the idea that animals evolve to occupy ecological niches, thereby avoiding interspecific competition for resources. Our results seem to infer that each predator species exhibit some flexibility in their feeding preferences but they each have a different 'portfolio' of suitable prey types (i.e. they are not indiscriminate), and they respond to changes of relative abundance of prey within their particular portfolio.

It should be acknowledged that the data available have many shortcomings, notably that $33 \%$ of stomach observations came from a single year (1984) and that trawl survey gears do not give a true picture of fish abundance in every case. Also it is important to recognise that with weak data we are likely draw some wrong conclusions, but this remains the first study to look at predator-prey relationships in the Celtic Sea.

Any relationships between predator preferences and prey availability apparent from the data, should be considered as being of the upmost importance since this could mean that fishing pressure exerted on a prey species (e.g. blue whiting and the industrial fleet) might have a significant indirect impact on predator stocks (e.g. hake and cod) or vice versa (Pinnegar et al., 2000). It is becoming increasingly apparent that individual fish stocks can not be managed in isolation and fishery managers are now being required to take into account wider ecological considerations (Botsford et al. 1997). Incorporation of complex feeding behavior, such as that described here, into fisheries models is considered crucial if we are ever make realistic fishery predictions in the future and manage fish stocks on a sustainable basis (Magnusson \& Palsson, 1991).

\section{ACKNOWLEDGEMENTS}

This work was funded by the European Community under Framework V, project contract QLRT-1999-01609 (Development of Structurally Detailed Statistically Testable models of marine populations, $\mathrm{DST}^{2}$ ), and the UK Department for Environment, Food \& Rural Affairs contract MF0316. 


\section{REFERENCES}

Anthony, J. A., Roby, D. D. \& Turco, K. R. (2000). Lipid content and energy density of forage fishes from the northern Gulf of Alaska. Journal of Experimental Marine Biology and Ecology, 248, 53-78.

Armstrong, M. J. (1982). The predator-prey relationships of Irish Sea poor-cod (Trisopterus minutus L.), pouing (Trisopterus luscus L.), and cod (Gadus morhua L.). Journal du Conseil International pour l'Exploration de la Mer, 40, 135-152.

Botsford, L. W., Castilla, J. C. \& Peterson, C. H. (1997). The management of fisheries and marine ecosystems. Science, 277, 509-515.

Bowman, R. E. (1986). Effect of regurgitation on stomach content data of marine fisheries. Environmental Biology of Fishes, 16, 171-181.

Cade, B. S. \& Richards, J. D. (1996). Permutation tests for least absolute deviation regression. Biometrics, 52, 886-902.

Cade, B. S., Terrell, J. W. \& Schroeder, R. L. (1999). Estimating effects of limiting factors with regression quantiles. Ecology, 80, 311-323.

Charnov, E. L. (1976). Optimal foraging: attack strategy of a mantid. American Naturalist, 110, 141-151.

Chesson, J., (1978). Measuring preference in selective predation. Ecology 59, 211-215.

Chesson, J., (1983). The estimation and analysis of preference and its relationship to foraging models. Ecology 64, 1297-1304.

Christensen, V, Walters, C. J. \& Pauly, D. (2000). Ecopath with Ecosim: a Users Guide, October 2000 Edition. Fisheries Centre, University of British Columbia, Vancouver, Canada and ICLARM, Penang, Malaysia. 130 p.

Cohen, J. E. \& Newman, C. M. (1988). Dynamic basis of food web organization. Ecology 69, $1655-1664$.

Confer, J. L. \& Moore, M. V. (1987). Interpretting selectivity indexes calculated from field data or conditions of prey replacement. Canadian Journal of Fisheries and Aquatic Science, 44, 1529-1533.

Conover, W. J. (1980). Practical Nonparametric Statistics. $2^{\text {nd }}$ edition, New York, Wiley.

Deb, D. (1997). Trophic uncertainty vs parsimony in food web research. Oikos, 78, 191-194.

Du Buit, M. H. (1982). Essai d'évaluation de la prédation de quelques téléostéens en Mer Celtique. Journal du Conseil International pour l'Exploration de la Mer, 40, 37-46.

Du Buit, M.H. (1992) Alimentation de la Cardine, Lepidorhombus whiffiagonis en Mer Celtique. Cah. Biol. Mar. 33, 501-514.

Du Buit, M. H. (1995). Food and feeding of cod (Gadus morhua L.) in the Celtic Sea. Fisheries Research, 22, 227-241.

Du Buit, M. H. (1996). Diet of hake (Merluccius merluccius) in the Celtic Sea. Fisheries Research, 28, 381-394.

Engås, A. \& Godø, O. R. (1989). Escape of fish under the fishing line of a Norwegian sampling trawl and its influence on survey results. Journal du Conseil International pour l'Exploration de la Mer, 45, 269-276.

Greenstreet, S. P. R., McMillan, J. A. \& Armstrong, E. (1998). Seasonal variation in the importance of pelagic fish in the diet of piscivorous fish in the Moray Firth, NE Scotland: a response to variation in prey abundance? ICES Journal of Marine Science, 55, 121-133.

Floeter, J. \& Temming, A. (2003). Explaining diet composition of North Sea cod (Gadus morhua): prey size preference vs. prey availability. Canadian Journal of Fisheries \& Aquaculture Science, 60, 140-150. 
Hart, P. J. B. \& Connellan, B. (1984). Cost of prey capture, growth rate and ration size in pike, Esox lucius L., as functions of prey weight. Journal of Fish Biology, 25, 279-292.

Hislop, J., Bromley, P. J., Daan, N., Gislason, H., Heessen, H. J. L., Robb, A. P., Skagen, D., Sparholt, H. \& Temming, A. (1997). Database report of the stomach sampling project 1991. ICES Cooperative Research Report, Number 219.

Ivlev, V. S. (1961). Experimental ecology of the feeding of fishes. Yale University Press, New Haven, CT. 302pp.

Jennings, S., Grrenstreet, S. P. R., Hill, L., Piet, G. J., Pinnegar, J. K. \& Warr, K. J. (2002). Long-term trends in the trophic structure of the North Sea fish community: evidence from stable-isotope analysis, size-spectra and community metrics. Marine Biology, 141: 10851097 ,

Juanes, F., Buckel, J. A. \& Scharf, F. S. (2002). Feeding ecology of piscivorous fishes. In Handbook of Fish and Fisheries (Hart P.J.B \& Reynolds, J.D. eds.) Volume 1, pp267283. Oxford, Blackwell Science.

Magnusson, K. G. \& Palsson, O. K. (1991). Predator-prey interactions of cod and capelin in Icelandic waters. ICES Marine Science Symposium, 193, 153-170.

Manly, B. F. J., Miller, P. \& Cook, L. M. (1972). Analysis of a selective predation experiment. American Naturalist 106, 719-736.

Marchal, P. \& Horwood, J. (1996). Long-term targets for the Celtic Sea mixed-species multimetiers fisheries. Aquatic Living Resources, 9, 81-94.

Mittelbach, G.C. (2002). Fish foraging and habitat choice: a theoretical perspective. In Handbook of Fish and Fisheries (Hart P.J.B \& Reynolds, J.D. eds.) Volume 1, pp251266. Oxford, Blackwell Science.

O’Neill, R.V. (1969). Indirect estimation of energy fluxes in animal food webs. Journal of Theoretical Biology, 22, 284-290.

Pearre, S. (1982). Estimating prey preference by predators: uses of various indices, and a proposal of another based on $\chi^{2}$. Canadian Journal of Fisheries \& Aquatic Science, 39, 914-923.

Pinnegar, J. K., Jennings, S., O’Brien, C.M. \& Polunin, N.V.C. (2002). Long-term changes in the trophic level of the Celtic Sea fish community and fish market price distribution. Journal of Applied Ecology, 39, 377-390.

Pinnegar, J. K., Polunin, N. V. C., Francour, P., Badalamenti, F., Chemello, R., HarmelinVivien, M-L., Hereu, B., Milazzo, M., Zabala, M., D’Anna, G. \& Pipitone, C. (2000). Trophic cascades in benthic marine ecosystems: lessons for fisheries and protected-area management. Environmental Conservation, 27, 179-200

Pope, J. G. (1991). The ICES multispecies assessment working group: evolution, insights, and future problems. ICES Marine Science Symposia 193, 22-33.

Scharf, F..S., Juanes, F. \& Rountree, R..A. (2000). Predator size-prey size relationships of marine fish predators: interspecific variation and effects of ontogeny and body size on trophic niche breadth. Marine Ecology-Progress Series, 208, 229-248.

Scharf, F. S., Juanes, F. \& Sutherland, M (1998). Inferring ecological relationships from the edges of scatter diagrams: comparison of regression techniques. Ecology, 79, 448-460.

Schoener, T. W. (1979). Generality of the size-distance relation in models of optimal feeding. American Naturalist, 114, 902-914.

Sih, A. \& Christensen, B. (2001). Optimal diet theory: when does it work, and when and why does it fail? Animal Behaviour, 61, 379-390.

Stephens, D. W. \& Krebs, J. R. (1986). Foraging Theory. Princeton, New Jersey: Princeton University Press. 
Van Pelt, T. I., Piatt, J. F., Lance, B. K. \& Roby, D. D. (1997). Proximate composition and energy density of some North Pacific forage fishes. Comparative Biochemistry \& Physiology, Series A. 118A, 1398.

Velasco, F. \& Oliva-Teles, A. (2000). Hake food consumption in the southern Bay of Biscay estimated from a gastric evacuation model. ICES-CM-2000/Q:11.

Warnes, S. \& Jones, B. W. (1995). Species Distributions from English Celtic Sea Grounfish Surveys, 1984-1991. Fisheries Research Technical Report No. 58. Ministry of Agriculture, Fisheries and Food, Directorate of Fisheries Research, Lowestoft, UK. 
Appendix 1. Number of predator stomachs containing identifiable fish prey

\begin{tabular}{lccccc}
\hline & \multicolumn{5}{c}{ Predator Species } \\
\cline { 2 - 6 } Year & Cod & Hake & Megrim & Saithe & Whiting \\
\hline 1977 & 5 & 19 & 17 & 0 & 45 \\
1978 & 0 & 25 & 16 & 3 & 64 \\
1979 & 12 & 4 & 8 & 16 & 2 \\
1981 & 33 & 57 & 22 & 35 & 38 \\
1982 & 43 & 25 & 12 & 0 & 0 \\
1983 & 3 & 202 & 223 & 0 & 66 \\
1984 & 669 & 187 & 146 & 0 & 627 \\
1985 & 46 & 365 & 317 & 42 & 69 \\
1986 & 0 & 126 & 54 & 0 & 53 \\
1987 & 7 & 5 & 1 & 13 & 0 \\
1988 & 0 & 59 & 29 & 0 & 0 \\
1991 & 61 & 232 & 106 & 186 & 92 \\
1992 & 26 & 48 & 43 & 6 & 65 \\
1993 & 43 & 28 & 93 & 17 & 32 \\
1994 & 1 & 3 & 11 & 0 & 0 \\
\hline Total & $\mathbf{9 4 9}$ & $\mathbf{1 3 8 5}$ & $\mathbf{1 0 9 8}$ & $\mathbf{3 1 8}$ & $\mathbf{1 1 5 3}$ \\
\hline
\end{tabular}

